Letter

\section{Paediatric olfactory dysfunction: a chance to detect COVID-19?}

We wish to challenge the assumption by COVID-19 researchers that olfactory dysfunction cannot be reviewed in children. ${ }^{1}$ Early identification of COVID-19 positive patients is key to limiting community spread and controlling the current global pandemic. New-onset anosmia was added to the primary screening symptoms for self-isolation after evidence emerged that it is an early symptom of COVID-19 infection. Official advice stipulates all individuals experiencing new-onset anosmia be presumed COVID-19 infected. Children were not excluded from this advice.

Anosmia is a highly specific and moderately sensitive screening symptom for COVID-19 infection in adults. ${ }^{2}$ To date, no published paediatric anosmia screening tools in COVID-19 have been validated. Simple screening questions regarding change or decrease in sense of smell and taste should however be included when screening children for possible COVID-19 infection. Symptoms reported by the child can potentially be used as a prompt for isolation and testing.

For young children, we advocate promoting olfactory education through play-based teaching to explore different types of smells, equipping children with language to describe smells and any changes they experience. This can be delivered simply and effectively with other health promotion teaching such as handwashing already occurring within schools and nurseries during the COVID-19 pandemic.

While the reported symptom of anosmia correlates with COVID-19 infection, self-reporting can miss cases of mild olfactory dysfunction in adult COVID-19.
The value of objective testing for olfactory dysfunction in paediatric COVID-19 is currently unclear and requires further investigation. Current understanding is limited by availability of age-appropriate paediatric reference ranges. ${ }^{3}$ With community engagement, this is an optimal time to encourage supporting research in this area.

Given the difficulties in discriminating COVID-19 from other common paediatric upper respiratory tract infections, it is possible to use existing anosmia assessment tools alongside olfactory screening questions. These could be performed by parents or medical professionals, within primary or secondary care or even be administered remotely with instruction. While scratch and sniff tests are widely validated and suitable for use, the unit price is likely prohibitive for mass screening. Future testing using limited panels of 'child-friendly' odours, for example, mint or banana on felt-pen like dispensers and other existing multi-use tests, would be suitable in a classroom setting. Additionally, jellybean or 'candy smell test' have been successfully used in children: a sweet is sucked or chewed while the child blocks their nose, they then release their nose to smell the sweet's flavour, identifying one of four possible choices provided. ${ }^{4}$ Other forms of gustatory screening using 'sweet, salty, sour and bitter' tastes or identifying sudden change in dietary preferences/ altered taste could also be used.

The importance of anosmia should not be underestimated as it may be the only discriminating symptom of COVID-19 to prompt early diagnostic testing in children and thereby prevent potential transmission. We appeal to researchers, clinicians, teachers and parents to consider reviewing this symptom in children to improve detection of COVID-19.

Andrew Hall $\odot,{ }^{1}$ Claire Frauenfelder, ${ }^{1}$ Colin Butler, ${ }^{1,2}$ Paula Coyle, ${ }^{1}$ Claire Hopkins ${ }^{3}$
'Department of Paediatric ENT, Great Ormond Street Hospital for Children, London, UK

${ }^{2}$ University College London Institute of Child Health, London, UK

${ }^{3}$ Department of Rhinology, King's College London, London, UK

Correspondence to Andrew Hall, Paediatric ENT, Great Ormond Street Hospital for Children, London WC1N 3JH, UK; andrew.hall@gosh.nhs.uk

Funding The authors have not declared a specific grant for this research from any funding agency in the public, commercial or not-for-profit sectors.

Competing interests None declared.

Provenance and peer review Not commissioned; internally peer reviewed.

This article is made freely available for use in accordance with BMJ's website terms and conditions for the duration of the covid-19 pandemic or until otherwise determined by BMJ. You may use, download and print the article for any lawful, non-commercial purpose (including text and data mining) provided that all copyright notices and trade marks are retained.

(c) Author(s) (or their employer(s)) 2021. No commercial re-use. See rights and permissions. Published by BMJ.

Check for updates

To cite Hall A, Frauenfelder C, Butler C, et al. Arch Dis Child 2021;106:e17.

Accepted 4 August 2020

Published Online First 20 August 2020

Arch Dis Child 2021;106:e17.

doi:10.1136/archdischild-2020-319971

ORCID iD

Andrew Hall http://orcid.org/0000-0002-4134-661X

\section{REFERENCES}

1 O'Donovan J, Tanveer S, Jones N, et al. Sniffing out the evidence for olfactory symptoms as a clinical feature of COVID-19: a systematic scoping review. Centre for Evidence-Based Medicine 2020.

2 Wee LE, Chan YFZ, NWY T, et al. The role of selfreported olfactory and gustatory dysfunction as a screening criterion for suspected COVID-19 [published online ahead of print, 2020 Apr 24]. Eur Arch Otorhinolaryngol 2020:1-2.

3 Calvo-Henríquez C, Chiesa-Estomba C, MartinezCapoccioni G, et al. Methods to assess olfaction in pediatric patients: a systematic review from the International YO-IFOS Study Group. Eur Arch Otorhinolaryngol 2020;277:313-21.

4 Renner B, Mueller CA, Dreier J, et al. The candy smell test: a new test for retronasal olfactory performance. Laryngoscope 2009;119:487-95. 